\title{
PENINGKATAN PRODUKTIVITAS PADA PROSES PRODUKSI PRACETAK DENGAN PENERAPAN METODE LEAN CONSTRUCTION UNTUK ELIMINASI WASTE
}

\author{
Yunita Dwi Setyastuti ${ }^{1}$, Sri Murni Dewi ${ }^{2}$, Agus Suharyanto ${ }^{3}$ \\ ${ }^{1}$ Mahasiswa / Program Magister / Teknik Sipil / Universitas Brawijaya \\ 2,3 Dosen / Teknik Sipil / Universitas Brawijaya \\ Korespondensi : yunitadwis.30@gmail.com
}

\begin{abstract}
PT. $X$ is one of the largest precast concrete industry in Indonesia, where to realize the vision, they continue to develop products and improve productivity performance by trying to improve quality of service, production process, and delivery product to customer with minimal cost and on time. To reach that purpose, needed Lean Construction method to eliminate waste and identify activities that can affect the products value-added.Research begins with description of the company's condition using Value Stream Mapping. Waste was identified by questionnaires, then analyzed by selection of mapping tools on Value Stream Analysis Tools and analyzed the root cause for suggestion of improvement. The results showed that the most critical waste that affectted productivity were defects (37.50\%), unnecessary inventory (25\%), and inappropiate processing (15\%). Lead time required for overall of the process was 479.56 minutes and after improvement was reduced to 463.83 minutes by unification T.III / T.IV (fixing and tightening of the bolt plate) which reduced non-value added 15.73 minutes.
\end{abstract}

Keywords : Lean Construction, Value Stream Mapping, Value Stream Analysis Tools, Critical Waste, Lead Time, Unification Process.

\section{PENDAHULUAN}

Industri konstruksi merupakan salah satu sektor ekonomi penting di Indonesia yang berkembang cukup pesat. Semakin berkembangnya industri konstruksi, menyebabkan meningkatnya daya saing untuk memenuhi permintaan pelanggan, sehingga muncul beberapa permasalahan yang membutuhkan solusi terbaik untuk meningkatkan efektifitas dan efisiensi.

Permasalahan yang sering terjadi adalah adanya kegiatan yang tidak memberikan nilai tambah, atau disebut pemborosan (waste). Menurut Alarcon (1995) dan Koskela (1992), pemborosan didefinisikan sebagai semua aktifitas yang memerlukan biaya, waktu, sumber daya, atau persediaan, baik secara langsung maupun tidak langsung, yang tidak memberikan nilai tambah pada produk akhir. Pemborosan yang terjadi akan mempengaruhi tingkat produktivitas. Menurunnya produktivitas umumnya disebabkan oleh lima jenis kegiatan yang tidak produktif, seperti menunggu, transportasi, proses lambat, pekerjaan tidak efektif, dan pekerjaan ulang.

PT. X merupakan salah satu industri beton pracetak terbesar di Indonesia, dimana untuk mewujudkan visinya, perusahaan terus mengembangkan produk dan meningkatkan kinerja produktivitasnya dengan berusaha meningkatkan kualitas dengan biaya minimal, serta tepat waktu, mulai dari pelayanan, proses produksi, hingga pengiriman produk ke pelanggan. Dalam upaya untuk mencapai tujuan tersebut, diperlukan suatu metode untuk mengetahui dan mengeliminasi aktivitas aktivitas yang tidak memberikan nilai tambah, serta memperpendek kebutuhan waktu proses. Salah satu metodenya yaitu Lean Construction. Istilah ini pertama kali digagas oleh Koskela (1992) yang menyatakan bahwa aktivitas pada proses produksi yang menambah nilai akan menjadi lebih efisien, sedangkan aktivitas yang tidak menambah nilai perlu untuk dikurangi atau dihilangkan. 
Penelitian ini akan dilakukan identifikasi dan eliminasi pemborosan yang terjadi pada proses produksi TP $\emptyset 50-\emptyset 60$. Beberapa hal yang perlu dipahami pada penelitian ini adalah bagaimana alur proses produksinya, apa saja yang menyebabkan munculnya pemborosan, dan bagaimana usulan perbaikan yang tepat untuk meminimalkan atau menghilangkan pemborosan, sehingga produktivitas perusahaan dapat tercapai.

\section{TINJAUAN PUSTAKA}

\subsection{Waste (Pemborosan)}

Menurut Shigeo Shingo (Hines \& Taylor, 2000), ada tujuh macam kategori pemborosan, yaitu produksi berlebih, cacat, persediaan tidak perlu, ketidaktepatan proses, ketidakefektifan transportasi, menunggu, dan pergerakan tidak perlu. Tipe aktivitas dalam perusahaan dibagi menjadi tiga, yaitu aktivitas bernilai tambah (VA), aktivitas tidak bernilai tambah (NVA), dan aktivitas tidak berilai tambah namun diperlukan (NNVA).

\subsection{Lean Construction}

Lean construction merupakan suatu cara untuk mendesain sistem produksi yang dapat meminimalisasi pemborosan dari pemakaian material, waktu, dan usaha dalam rangka menghasilkan jumlah nilai yang maksimum (Koskela et al., 2002). Mindset dalam Lean dikenal dengan slogan "Going to Zero", yaitu tidak ada cacat, pekerjaan ulang, alat berhenti/ rusak, proses tidak efektif, sumber daya kurang, kecelakaan kerja, dan lainnya (Anwar, 2014)

\subsection{Peta Aliran Nilai (Value Stream Mapping/ VSM)}

VSM merupakan alat pemetaan yang digunakan untuk menyusun keadaan saat ini dari sebuah proses dengan cara mengidentifikasi aktivitas yang bernilai dan tidak bernilai tambah, sehingga mempermudah untuk mencari akar permasalahannya. Manfaat VSM adalah untuk membantu memperbaiki sebuah proses secara menyeluruh dan meningkatkan efisiensi dan efektifitas proses produk. Ada 3 bagian utama dalam VSM, yaitu:

a. Aliran informasi

b. Aliran fisik/ proses produksi

c. Jarak tempuh

\subsection{Perangkat Analisa Aliran Nilai} (Value Stream Analysis Tools/ VALSAT)

VALSAT merupakan suatu metodologi untuk membuat alur proses menjadi lebih efektif. Menurut Hines dan Rich (1997), ada 7 macam alat pemetaan yang paling umum digunakan yang dapat dilihat pada matriks VALSAT (Tabel 1). Ketujuh alat ini didasarkan atas upaya untuk mempresentasikan ketujuh jenis pemborosan, yaitu dengan memilih alat yang paling dominan untuk memetakan pemborosan tersebut.

Tabel 1. Matriks VALSAT

\begin{tabular}{|c|c|c|c|c|c|c|c|}
\hline \multirow[b]{2}{*}{$\begin{array}{l}\text { Waste/ } \\
\text { Structure }\end{array}$} & \multicolumn{7}{|c|}{ Mapping Tools } \\
\hline & $\begin{array}{l}\text { Process } \\
\text { Actvivity } \\
\text { Mapping }\end{array}$ & $\begin{array}{c}\text { Supply Chain } \\
\text { Response } \\
\text { Matrix }\end{array}$ & $\begin{array}{c}\text { Production } \\
\text { Variety } \\
\text { Funnel }\end{array}$ & $\begin{array}{c}\text { Quality } \\
\text { Filter } \\
\text { Mapping }\end{array}$ & $\begin{array}{c}\text { Demand } \\
\text { Amplification } \\
\text { Mapping }\end{array}$ & $\begin{array}{c}\text { Decision } \\
\text { Point } \\
\text { Analysis }\end{array}$ & $\begin{array}{l}\text { Physical Stucture } \\
\text { (a) Volume } \\
\text { (b) Value }\end{array}$ \\
\hline Overproduction & L & $\mathrm{M}$ & & $\mathrm{L}$ & $\mathrm{M}$ & $\mathrm{M}$ & \\
\hline Time Waiting & $\mathrm{H}$ & $\mathrm{H}$ & $\mathrm{L}$ & & M & M & \\
\hline $\begin{array}{l}\text { Transport } \\
\text { Inappropiate }\end{array}$ & $\mathrm{H}$ & & & & & & $\mathrm{L}$ \\
\hline $\begin{array}{l}\text { Processing } \\
\text { Unnecessary }\end{array}$ & $\mathrm{H}$ & & M & $\mathrm{L}$ & & $\mathrm{L}$ & \\
\hline $\begin{array}{l}\text { Inventory } \\
\text { Unnecessary }\end{array}$ & M & $\mathrm{H}$ & M & & $\mathrm{H}$ & M & $\mathrm{L}$ \\
\hline Motion & $\mathrm{H}$ & $\mathrm{L}$ & & & & & \\
\hline Product Defect & $\mathrm{L}$ & & & $\mathrm{H}$ & & & \\
\hline $\begin{array}{l}\text { Overall } \\
\text { Structure }\end{array}$ & $\mathrm{L}$ & $\mathrm{L}$ & $\mathrm{M}$ & $\mathrm{L}$ & $\mathrm{H}$ & $\mathrm{M}$ & $\mathrm{H}$ \\
\hline Origin of Tool & $\begin{array}{c}\text { Industrial } \\
\text { Engineering }\end{array}$ & $\begin{array}{c}\text { Time } \\
\text { compression/ } \\
\text { Logistics }\end{array}$ & $\begin{array}{c}\text { Operation } \\
\text { Management }\end{array}$ & New Tool & $\begin{array}{l}\text { System } \\
\text { Dynamics }\end{array}$ & $\begin{array}{c}\text { Efficient } \\
\text { Consumer } \\
\text { Response/ } \\
\text { Logistics }\end{array}$ & New Tool \\
\hline
\end{tabular}

Catatan :

$\mathrm{H} \rightarrow$ faktor pengali $=9$

$\mathrm{M} \rightarrow$ faktor pengali $=3$

$\mathrm{L} \rightarrow$ faktor pengali $\quad=1$

\subsection{Root Cause Analysis (Analisa Akar Penyebab) \\ RCA adalah alat yang berfokus pada} penemuan akar penyebab suatu masalah dengan tujuan untuk memperbaiki atau menghilangkan akar penyebab dari suatu masalah dan mencegah masalah muncul kembali. RCA didesain untuk mengidentifikasi penyebabpenyebab yang berhubungan dengan $5 \mathrm{M}$, yaitu manusia, alat, material, metode, dan sistem manajemen, serta mengetahui masalah-masalah yang berhubungan dengan reliabilitas proses, ketersediaan, dan pemeliharaan.

\section{METODE PENELITIAN}

\subsection{Bagan Alur Penelitian}

Gambar 1. 


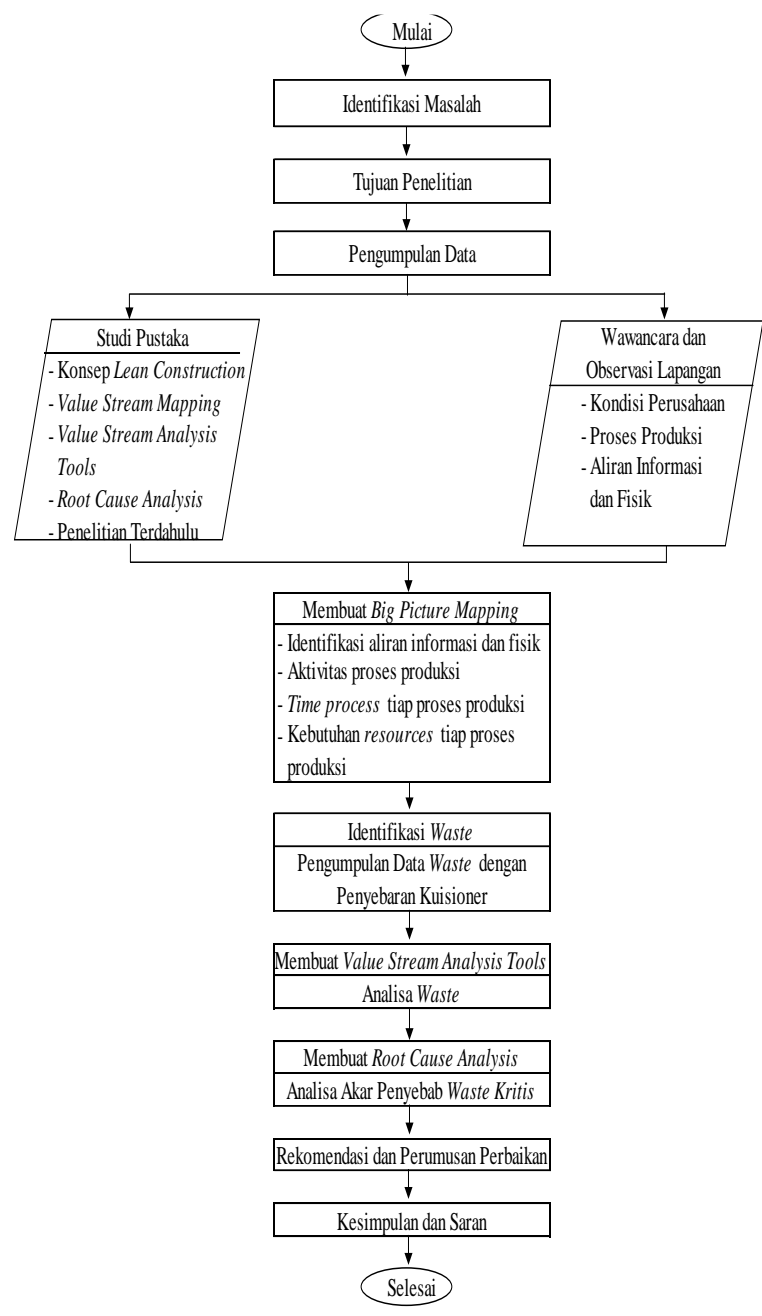

Gambar 1. Bagan alur penelitian

\subsection{Identifikasi Awal}

Tahap identifikasi awal merupakan tahap untuk mengetahui permsalahan yang menjadi objek penelitian. Observasi lapangan (awal) bertujuan untuk mengetahui kondisi nyata yang terjadi di pabrik, seperti sistem penjadwalan order, kondisi material, sistem kerja karyawan, alur produksi, dan permasalahan yang dihadapi, sehingga didapatkan rumusan masalah untuk dilakukan penelitian, yaitu :

1. Mengidentifikasi pemborosan selama proses yang mempengaruhi produktivitas.

2. Mengeliminasi pemborosan dengan pembuatan usulan perbaikan, sehingga produktivitas tercapai.

\subsection{Pengumpulan dan Pengolahan Data}

Tahap pengumpulan dan pengolahan data dilakukan dengan observasi lapangan, wawancara langsung dengan pihak terkait, dan penyebaran kuisioner. Adapun langkahlangkahnya adalah sebagai berikut :
1. Penggambaran peta aliran nilai (VSM)

Penggambaran ini dilakukan untuk memahami kondisi pabrik, sehingga mempermudah pemahaman aliran proses dan keseluruhan aktivitas produksi. Data proses produksi dan waktu proses didapat melalui observasi lapangan dan wawancara. Langkah-langkah VSM adalah sebagai berikut :

- Mengumpulkan data-data yang dibutuhkan dalam proses produksi.

- Mengetahui pencapaian akhir yang dihasilkan dari sistem produksi.

- Mengetahui tahapan-tahapan dalam proses produksi.

2. Penyebaran kuisioner

Penyebaran kuisioner dilakukan untuk identifikasi pemborosan yang ada di proses produksi yang diisi oleh para pelaku yang fokus pada produksi TP $\emptyset 50-\emptyset 60$, antara lain manajer produksi, asisten manajer, dan koordinasi kepala jalur. Penyebaran kuisioner menggunakan sistem Waste Workshop, yaitu aktivitas yang dilakukan untuk memperoleh data/ informasi yang berkaitan dengan pemborosan melalui penyebaran kuisioner sekaligus wawancara terhadap responden.

3. Pembobotan tujuh pemborosan dan analisa VALSAT

Setelah data pemborosan didapatkan, selanjutnya dilakukan pembobotan untuk mengetahui pemborosan yang paling dominan terjadi sepanjang aliran proses. Kemudian, dilakukan pemilihan alat pemetaan yang dominan untuk analisa pemborosan dengan VALSAT.

4. Perbaikan proses dan eliminasi pemborosan

Setelah dilakukan analisa pemborosan, selanjutnya dilakukan identifikasi dan analisa akar penyebab dari pemborosan kritis dengan RCA. Kemudian, dilakukan langkah perbaikan untuk meminimasi pemborosan guna mencapai perbaikan yang sesuai dengan keinginan.

\section{HASIL DAN PEMBAHASAN}

4.1 Peta Aliran Nilai Saat Ini (Current State Value Stream Mapping/ CSVSM )

CSVSM merupakan konfigurasi aliran produk saat ini. Data didapat dari hasil wawancara langsung dengan pihak terkait 
untuk mendapatkan data informasi dan total kebutuhan waktu pemesanan, serta observasi lapangan dengan mengamati dan mencatat waktu yang dibutuhkan pada tiap proses dengan bantuan stopwatch dan diambil dari hari yang berbeda-beda selama 14 hari, kemudian diambil rata-rata total dari masingmasing rata-rata per hari. CSVSM proses produksi TP $\emptyset 50-\emptyset 60$ dapat dilihat pada Gambar 2.

\subsection{Identifikasi Pemborosan}

Langkah selanjutnya setelah dilakukan pemetaan adalah identifikasi pemborosan dengan menyebarkan kuisioner yang diisi oleh responden yang terlibat langsung dalam proses produksi TP $\emptyset 50-\emptyset 60$. Kuisioner ini diberikan pengertian pemborosan secara umum dan pengisian didampingi oleh peneliti, agar responden memahami maksud dari kuisioner tersebut. Hasil identifikasi pemborosan dapat dilihat pada Gambar 3.

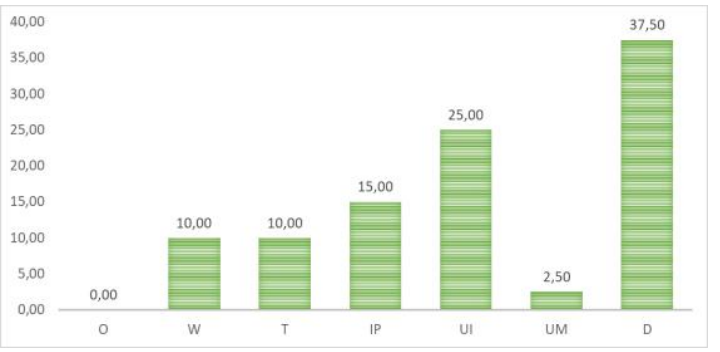

Berdasarkan grafik diatas, didapatkan 3 skor rata-rata tertinggi, yaitu cacat $(37,50 \%)$, persediaan tidak perlu $(25,00 \%)$, dan ketidaktepatan proses $(15,00 \%)$.

\subsection{Analisis VALSAT}

Setelah mendapatkan skor dari masingmasing pemborosan, selanjutnya dilakukan pemilihan alat pemetaan yang efektif untuk analisis pemborosan secara detail dengan mengalikan skor rata-rata tiap pemborosan dengan matriks VALSAT. Peringkat hasil VALSAT dapat dilihat pada Tabel 2.

Tabel 2. Peringkat hasil VALSAT

\begin{tabular}{|llcccc}
\hline No. & \multicolumn{1}{|c}{ Mapping Tools } & Total & Persentase & $\begin{array}{c}\text { Akumulasi } \\
\text { Persentase }\end{array}$ & Ranking \\
\hline 1 & Process Activity Mapping & 450,00 & 27,11 & 27,11 & 1 \\
2 & Supply Chain Response Matrix & 317,50 & 19,13 & 46,23 & 3 \\
3 & Production Variety Furnel & 130,00 & 7,83 & 54,07 & 5 \\
4 & Quality Filter Mapping & 352,50 & 21,23 & 75,30 & 2 \\
5 & Demand Amplification Mapping & 255,00 & 15,36 & 90,66 & 4 \\
6 & DecisionPoirt Aralysis & 120,00 & 7,23 & 97,89 & 6 \\
7 & Physical Struture & 35,00 & 2,11 & 100,00 & 7 \\
\hline \multicolumn{7}{|c}{ TOTAL } & $\mathbf{1 6 6 0 , 0 0}$ & $\mathbf{1 0 0 , 0 0}$ \\
\hline \multicolumn{5}{|c}{} \\
\hline
\end{tabular}

Berdasarkan tabel diatas, dipilih 3 peringkat teratas VALSAT untuk analisis pemborosan yang terjadi, yaitu Process Activity Mapping (27,11\%), Quality Filter Mapping $(21,23 \%)$, dan Supply Chain Response Matrix $(19,13 \%)$.

Gambar 3 Hasil Identifikasi Waste

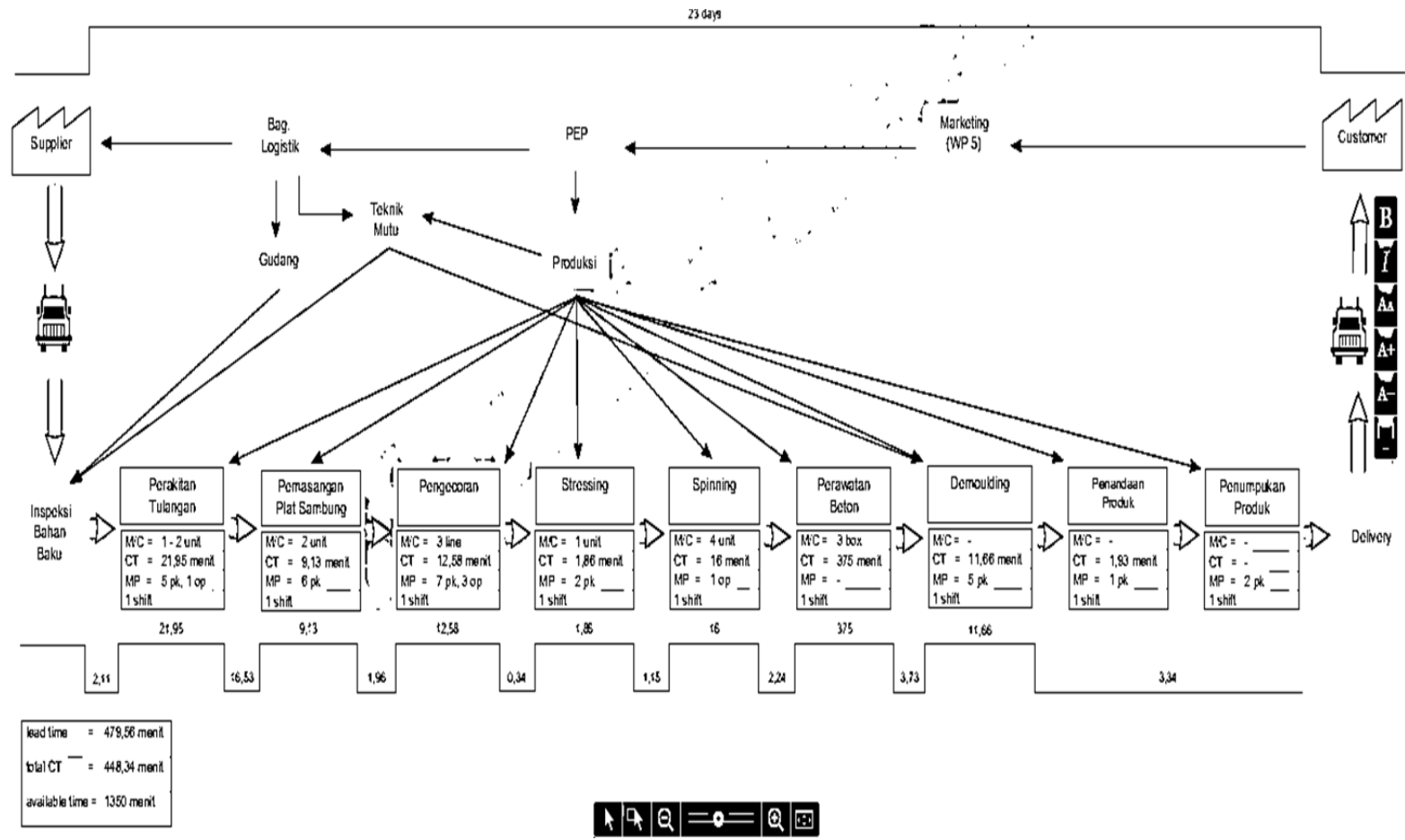

Gambar 2. Peta aliran nilai saat ini 


\subsubsection{Peta Proses Aktivitas \\ Activity Mapping/ PAM)}

(Process

PAM merupakan alat untuk merekam seluruh aktivitas dari suatu sistem, serta mengurangi aktivitas yang tidak memberikan nilai tambah, kemudian dilakukan penyederhanaan agar dapat mengurangi pemborosan. Berdasarkan pemetaan PAM diketahui jumlah aktivitas secara keseluruhan, sehingga didapat aktivitas yang bernilai dan tidak bernilai tambah. Serta, diketahui kebutuhan waktu yang dibutuhkan tiap aktivitas yang dapat dilihat pada Tabel 3 dan Gambar 4.

Tabel 3. Jumlah aktivitas dan kebutuhan waktu

\begin{tabular}{lccccc} 
Jenis Aktivitas & $\mathbf{0}$ & $\mathbf{T}$ & $\mathbf{I}$ & $\mathbf{S}$ & $\mathbf{D}$ \\
\hline Jumlah Aktivitas & 13 & 12 & 0 & 2 & 2 \\
Persentase & 44,83 & 41,38 & 0,00 & 6,90 & 6,90 \\
\hline Waktu (menit) & 450,09 & 13,13 & 0,00 & 3,52 & 12,82 \\
Persentase & 93,86 & 2,74 & 0,00 & 0,73 & 2,67 \\
\hline \multicolumn{1}{c}{ VA } & & 44,83 & & \\
NVA/NNVA & & 55,17 & & \\
\hline Ket : & & & \\
O = Operation & $\mathrm{T}=$ Transportation & I = Inspection & \\
S = Storage & D = Delay & &
\end{tabular}

PERSENTASE JUMLAH TIAP KLASIFIKASI

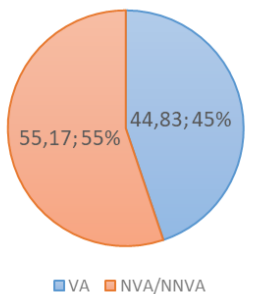

Gambar 4. Persentase jumlah aktivitas

Berdasarkan tabel diatas, didapat jumlah aktivitas bernilai tambah sebanyak 13 dengan kebutuhan waktu sebesar 450,09 menit, sedangkan jumlah aktivitas tidak bernilai tambah sebanyak 16 dengan kebutuhan waktu sebesar 29,47 menit. Ringkasan analisa PAM dapat dilihat pada Tabel 4.

\subsubsection{Peta Cacat Kualitas (Quality Filter Mapping/ QFM)}

QFM merupakan alat untuk mengidentifikasi adanya masalah cacat kualitas yang terjadi sepanjang rantai pasokan. Pada penelitian ini, cacat yang digambarkan hanya cacat kualitas pada produk yang ditemukan pada saat proses inspeksi setelah produk jadi. Berikut grafik QFM produk cacat dapat dilihat pada Gambar 5.

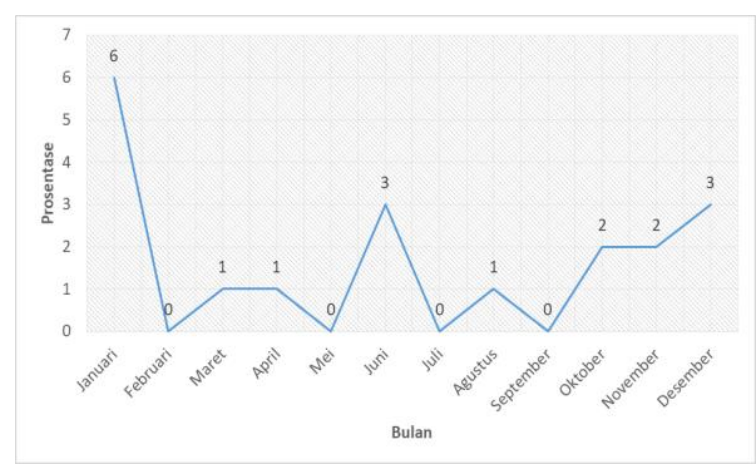

Gambar 5. Grafik QFM produk cacat

Berdasarkan grafik QFM didapat cacat produk terbesar terjadi pada bulan Januari dengan persentase sebesar $31,58 \%$. Penyebab cacat produk rata-rata terjadi karena kurang maksimalnya pemerataan adukan beton dan air semen keluar melalui bibir cetakan yang disebabkan oleh kurang ketelitian pekerja dan alat kurang efektif dalam pengoperasiannya, sehingga menyebabkan ketika produk sudah jadi, terjadi burik dan keropos di sebagian badan beton.

\subsubsection{Matriks Rantai Pasokan (Supply Chain Response Matrix/ SCRM) \\ SCRM merupakan alat pemetaan yang} digunakan untuk mengidentifikasi dan mengevaluasi jumlah persediaan yang dibutuhkan dan kebutuhan waktu yang tersedia. Data yang digunakan dalam pembuatan SCRM adalah data kedatangan dan kebutuhan material bahan baku per hari, data hasil produk jadi per hari, dan data pengiriman produk per hari. Berikut perhitungan SCRM yang dapat dilihat pada Tabel 5 dan Gambar 6.

Tabel 5. Perhitungan SCRM

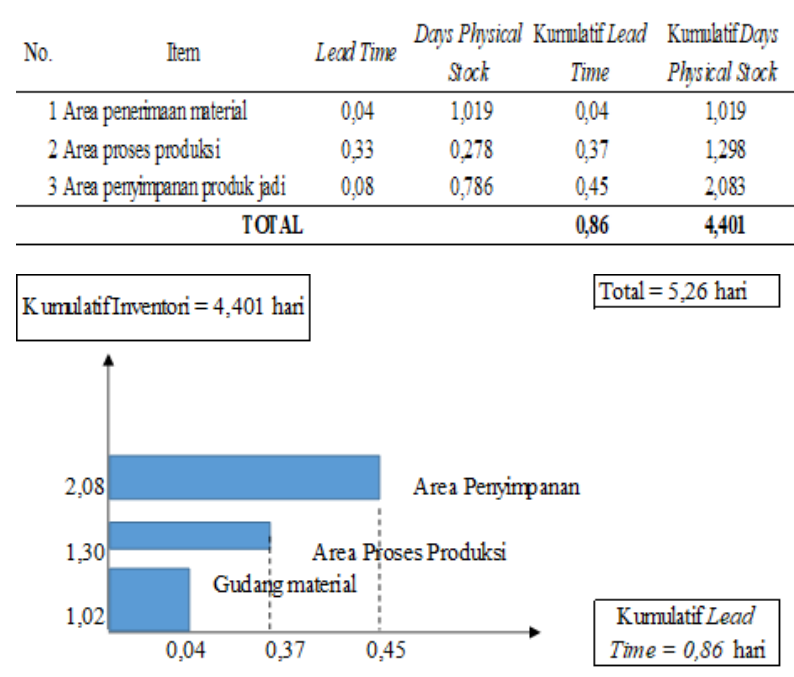

Gambar 6. Grafik SCRM 
Tabel 4. Ringkasan analisa PAM

\begin{tabular}{|c|c|c|c|}
\hline No. & Jenis Aktivitas & $\begin{array}{c}\text { PAM (Jumlah/ } \\
\text { Waktu) }\end{array}$ & Analisa \\
\hline 1 & Operation & \begin{tabular}{c|}
13 \\
$\mathbf{4 4 , 8 3} \%$ \\
450,09 menit \\
$\mathbf{9 3 , 8 6 \%}$ \\
\end{tabular} & $\begin{array}{l}\text { Aktivitas operasi merupakan aktivitas yang bernilai tambah, sehingga perlu } \\
\text { dijaga konsistensi prosesıya. Aktivitas operasi ini memakan waktu selama } 450 \text {, } \\
09 \text { menit }(93,86 \%) \text {. Aktivitas terlama adalah pada proses perawatan beton } \\
\text { yaitu selama } 375 \text { menit. }\end{array}$ \\
\hline 2 & Transportation & $\begin{array}{l}13,13 \text { menit } \\
\mathbf{2 , 7 4} \% \\
\end{array}$ & $\begin{array}{l}\text { Jumlah aktivitas transportasi yang digunakan cukup banyak, yakni } 12 \\
(41,38 \%) \text {. Hal ini dikarenakan tiap perpindahan proses, diperlukan proses } \\
\text { handling, baik dengan jarak relatif pendek maupun panjang. Perbaikan untuk } \\
\text { efisiensi waktu transportasi tidak berdampak signifikan, dikarenakan waktu } \\
\text { yang dibutulhkan harya } \pm 2,7 \% \text { dari total waktu. }\end{array}$ \\
\hline 3 & Inspection & $\begin{array}{c}0 \\
0 \% \\
0 \text { menit } \\
0 \%\end{array}$ & $\begin{array}{l}\text { Inspeksi merupakan aktivitas added valu. Namun dalam proses ini, inspeksi } \\
\text { dilakukan diluar alur proses, yaitu ketika bahan baku datang dari supplier dan } \\
\text { ketika produk sudah jadi (masa curing di stockyard) dan siap untuk dikirim, } \\
\text { sehingga jumlah aktivitas dianggap } 0 \% \text {. }\end{array}$ \\
\hline 4 & Storage & $\begin{array}{c}2 \\
\mathbf{6 , 9 0 \%} \\
3,52 \text { menit } \\
\mathbf{0 , 7 3} \%\end{array}$ & $\begin{array}{l}\text { Penyimpanan merupakan aktivitas dengan jumlah waktu yang dibutuhkan hanya } \\
\pm 0,7 \% \text {, sehingga perubahannya tidak berdampak signifikan terhadap } \\
\text { keseluruhan ahur proses. }\end{array}$ \\
\hline & Delay & \begin{tabular}{c|}
2 \\
$\mathbf{6 , 9 0 \%}$ \\
12,82 menit \\
$\mathbf{2 , 6 7 \%}$
\end{tabular} & $\begin{array}{l}\text { Delay merupakan aktivitas non-value added dengan jumlah } 2(6,90 \%) \text {. Hal ini } \\
\text { terjadi karena adanya perbedaan cycle time antar proses. Perbaikan yang } \\
\text { dilakukan untuk mengurangi delay adalah dengan melakukan keseimbangan } \\
\text { proses. }\end{array}$ \\
\hline
\end{tabular}

Berdasarkan grafik SCRM didapatkan jumlah kebutuhan waktu kumulatif sebesar 0,86 hari dengan persediaan kumulatif sebesar 3,79 hari, sehingga total waktu dalam rantai pasokan adalah sebesar 4,65 hari.

\subsection{Analisis Akar Penyebab (RCA) dengan Diagram Tulang Ikan \\ Pada penelitian ini, metode yang} digunakan untuk analisis akar penyebab adalah diagram tulang ikan. Identifikasi masalah utama untuk dicari akar penyebab didasarkan pada pemborosan kritis dari hasil identifikasi pemborosan yang dapat dilihat pada Gambar 7 .

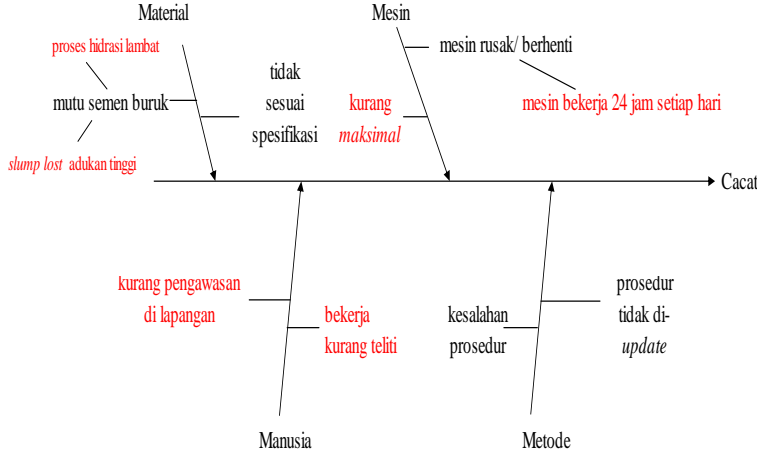

(a)

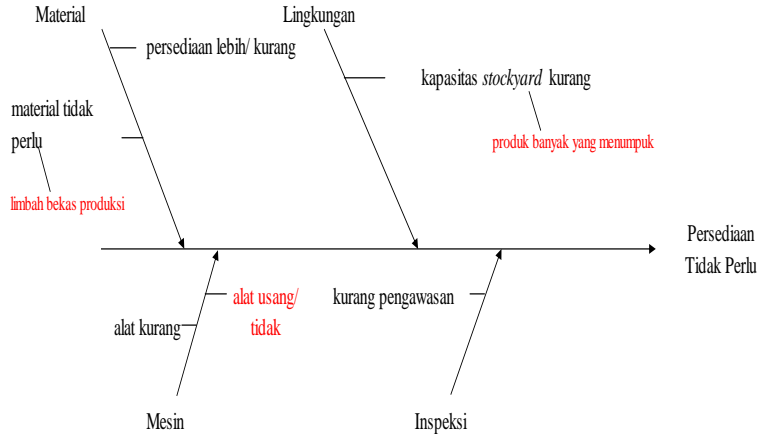

(b)

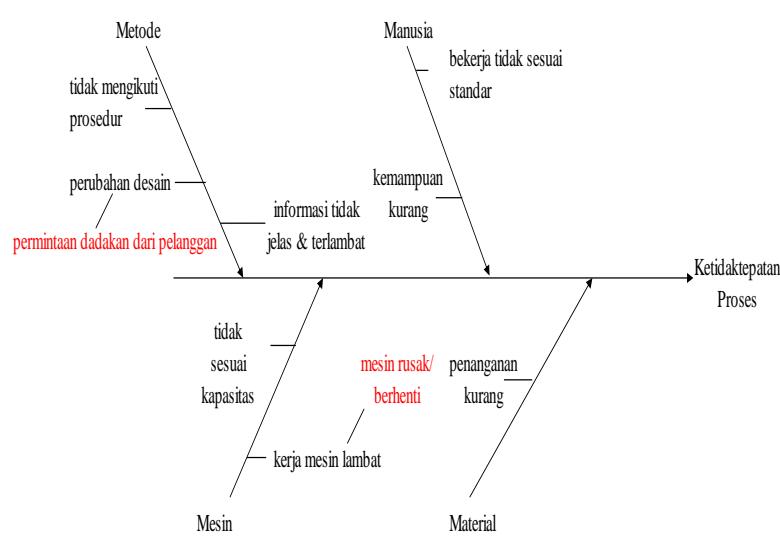

(c)

Gambar 7. Analisa akar penyebab dengan fishbone diagram 
Pada Gambar 7.a menunjukkan bahwa faktor-faktor penyebab cacat antara lain material, manusia, mesin, dan metode, dengan akar penyebab dominan dari tiap faktor yaitu (a.1) mutu semen kurang baik, (a.2) kurang pengawasan di lapangan dan karyawan kurang teliti dalam bekerja, (a.3) mesin rusak/ berhenti dan bekerja kurang maksimal.

Pada Gambar 7.b menunjukkan bahwa faktor-faktor penyebab persediaan tidak perlu antara lain material, mesin, lingkungan, dan inspeksi, dengan akar penyebab dominan dari tiap faktor yaitu (b.1) terdapat beberapa material tidak perlu di sekitar area kerja, (b.2) terdapat alat usang/ tidak terpakai di sekitar area kerja karena beberapa pesanan produk tidak menggunakan alat tersebut, (b.3) kapasitas stockyard tidak mencukupi karena banyaknya produk menumpuk.

Pada Gambar 7.c menunjukkan bahwa faktor-faktor penyebab ketidaktepatan proses antara lain metode, mesin, manusia, dan material, dengan akar penyebab dominan dari tiap faktor yaitu (c.1) terjadi perubahan desain karena permintaan dadakan dari pelanggan dan (c.2) kerja mesin lambat.

\subsection{Rekomendasi Perbaikan}

Tujuan pembuatan usulan rekomendasi perbaikan adalah untuk mengeleminasi pemborosan yang ada dengan memberikan beberapa saran. Bisa dikatakan bahwa pemberian usulan rekomendasi perbaikan ini digunakan supaya pemborosan tidak terjadi lagi dikemudian hari.

\subsubsection{Penggabungan Proses T.III dan T.IV (Pemasangan Plat Sambung dan Pengencangan Baut Plat Sambung)}

Dari analisis CSVSM dan PAM, ditemukan ketidaktepatan proses, yaitu adanya kegiatan menunggu untuk proses pemasangan plat sambung dan pengencangan baut plat sambung selama 11 menit (total waktu 2 proses). Tujuan penggabungan proses T.III dan T.IV adalah untuk efisiensi waktu dan alur proses. Berikut alur sebelum dan sesudah perbaikan dapat dilihat pada Gambar 8.

Pada Gambar 8.a, total waktu yang dibutuhkan adalah 49,71 menit dengan kebutuhan waktu untuk perpindahan komponen dari T.I ke T.III, T.III ke T.II, dan T.II ke T.IV dengan menggunakan hoist selama 3,71 menit, serta aktivitas menunggu untuk pemasangan plat sambung dan pengancangan baut plat sambung selama 12,82 menit. Pada Gambar 8.b, terjadi pengurangan waktu sebanyak 13,62 menit, dengan dilakukan pengurangan proses (dari T.I ke T.III dan dari T.III ke T.II) dan menghilangkan aktivitas menunggu, serta penambahan 1 alat pengencangan Mur Rod Simultan dan pemerataan sumber daya manusia pada lokasi di T.III-T.IV, sehingga didapatkan total waktu menjadi 33,98 menit.

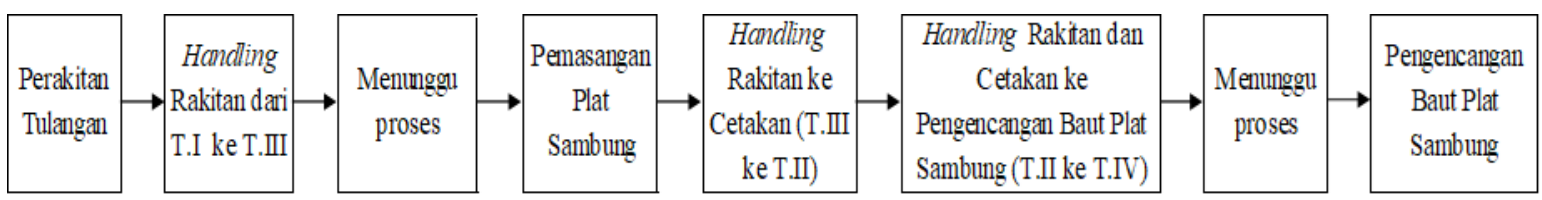

(a)

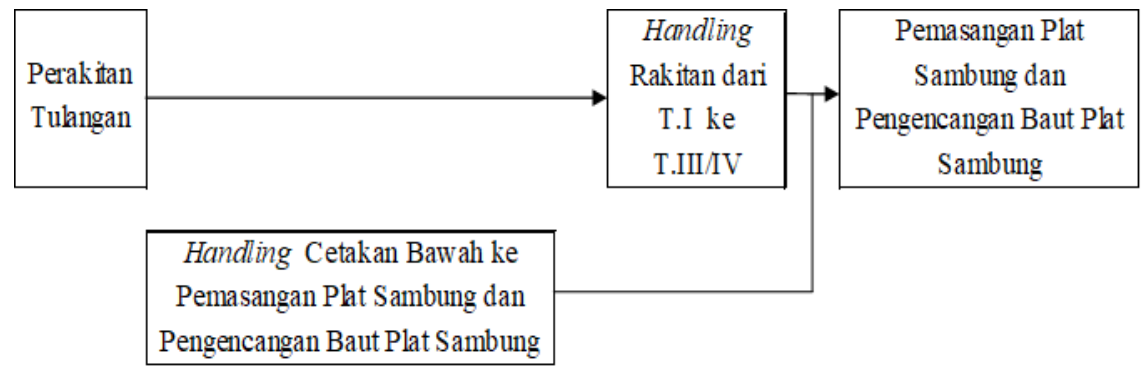

(b)

Gambar 8. Alur proses sebelum dan sesudah perbaikan 


\section{KESIMPULAN DAN SARAN}

\subsection{Kesimpulan}

Berdasarkan hasil penelitian, maka dapat disimpulkan hal-hal sebagai berikut :

1. Aktifitas - aktifitas dominan yang tidak memberikan nilai tambah yang dapat mempengaruhi peningkatan produktivitas yaitu cacat $(37,50 \%)$, persediaan tidak perlu $(25 \%)$, dan ketidaktepatan proses (15\%).

2. Cara perbaikan untuk mengurangi pemborosan yang terjadi adalah :

a. Penggabungan proses di T.III dan T.IV (pemasangan dan pengencangan baut plat sambung) dapat mengurangi waktu nonvalue added sebesar 15,73 menit, sehingga total waktu keseluruhan proses dari 479,56 menit berkurang menjadi 463,83 menit.

b. Rekomendasi perbaikan untuk cacat yaitu dilakukan (a.1) inspeksi dan uji trial material terlebih dahulu, (a.2) inspeksi langsung di lapangan untuk mengetahui proses kerja di lapangan, apakah sesuai prosedur atau tidak, serta (a.3) perawatan dan kontrol mesin secara berkala setiap 1 bulan, jika mesin rusak parah, maka perlu diganti baru.

c. Rekomendasi perbaikan untuk persediaan tidak perlu yaitu (b.1) limbah material segera dibuang agar tidak terjadi penumpukan sisa material di area kerja karena hal itu akan mengganggu pergerakan proses kerja, (b.2) alat yang tidak terpakai harus segera dipindahkan agar tidak mengganggu pergerakan proses produksi di area kerja, dan (b.3) dilakukan konfirmasi setelah produk siap untuk didistribusikan dan dilakukan toleransi batas tenggang \pm 10 hari. Jika produk tidak diambil lebih dari batas waktu toleransi, maka produk tetap harus dikirim.

d. Rekomendasi perbaikan untuk ketidaktepatan proses yaitu (c.1) desain dibuat diluar siklus produksi, sehingga tidak memengaruhi jalannya produksi desain awal dan (c.2) dilakukan perawatan dan kontrol mesin secara berkala setiap 1 bulan, jika mesin rusak parah, maka perlu diganti baru.

\subsection{Saran}

Dari hasil penelitian, saran yang dapat disampaikan oleh peneliti adalah sebagai berikut:

1. Perlu dilakukan pertimbangan kembali dalam mengefisiensikan waktu proses selain penggabungan proses pemasangan plat sambung, seperti perubahan sistem uap pada perawatan beton dari suhu rendah menjadi suhu tinggi atau menggunakan sistem perawatan hidrotermal, yaitu memanaskan cetakan untuk beton pracetak selama 4 jam pada suhu $65^{\circ} \mathrm{C}$, atau menggunakan sinar inframerah selama 2-4 jam pada suhu $90^{\circ} \mathrm{C}$. Hal ini dilakukan supaya target produksi per hari dapat tercapai.

2. Dalam menentukan rekomendasi perbaikan, perlu diperhatikan tentang dampak, biaya, dan risiko, sehingga diketahui seberapa besar pengaruh perbaikan terhadap eliminasi pemborosan.

3. Diharapkan untuk kegiatan penelitian selanjutnya, perlu dilakukan evaluasi rekomendasi perbaikan setelah dilakukan pembuatan usulan perbaikan. Tujuannya untuk menguji apakah usulan tersebut berhasil atau perlu dilakukan perbaikan kembali.

\section{DAFTAR PUSTAKA}

[1] Anwar, Riyantono. 2014. Belajar Lean. Jakarta: Manajemen Operation.

[2] Hines, P. and Rich, N. 1997. The Seven Value Stream Mapping Tools. International Journal of Operations \& Production Management, Vol. 17 No.1, pp. 46-64

[3] Hines, P. and Taylor, D. 2000. Going Lean. Lean Enterprise Research Center Cardiff Bussiness School, USA.

[4] Koskela, L. 1992. Application of The New Production Philosophy to Construction. Stanford University, CIFE Technical Report \#72.

[5] Koskela, L., et al. 2002. The Foundation of Lean Construction. In: Best R., and Valence, G. D., eds. Design and Construction: Building in Value, Butterworth-Heinemann. 211-255.

[6] Vorley, Geoff. 2008. Mini Guide to Root Cause Analysis. Guildford Surrey United Kingdom: Quality Management \& Training.

[7] Yudakusumah, Teguh. 2012. Aplikasi Lean Construction untuk Meningkatkan Efisien Waktu Pada Proses Produksi di Industri Precast. Universitas Indonesia: Tesis. 